\title{
As relações de troca em região de fronteira: uma proposta metodológica sob a ótica convencionalista
}

\author{
Cláudio Zarate Max * \\ Tito Carlos Machado de Oliveira**
}

\section{Resumo}

Os estudos sobre a realidade econômica, social e cultural das regiões periféricas denominadas zonas de fronteira constituem em desafios de difícil articulação e consenso. Para análise da coordenação econômica, o mecanicismo do sistema de preços se torna insuficiente - se tratado com único meio de coordenação em face da pluralidade de processos de articulação e interação que envolve os atores, os territórios e as instituições culturalmente diferenciados. $\mathrm{O}$ aporte teórico da economia das convenções revela-se em um instrumento importante para tratar de aspectos que envolvem o grau de confiança, as reciprocidades, os acordos tácitos e os julgamentos de valor numa clara aproximação entre as ciências econômicas, sociais e políticas. $\mathrm{O}$ objetivo do presente trabalho é a de propor uma reflexão teórica baseada na abordagem convencionalista sobre os mecanismos de coordenação dos atores de distintos territórios fronteiriços.

Palavras-chave: Fronteira; Economia das convenções; Comercialização; Territórios.

\footnotetext{
* Mestrando em Agronegócios - Universidade Federal de Mato Grosso do Sul (claudiozarate@uol.com.br).

** Professor Doutor em Geografia Humana/Universidade Federal de Mato Grosso do Sul (tito.ufms@gmail.com).
}

Geosul, Florianópolis, v. 24, n. 47, p 7-27, jan./jun. 2009 
MAX, C.Z. \& OLIVEIRA, T.C.M. de. As relações de troca em região de ...

The relationships of change in area of border: a methodological proposal under the conventionalist optics

\begin{abstract}
The studies about the economical, social and cultural reality of the outlying border zones are constituted in challenges of difficult articulation and consensus. For the economical coordination analysis, the exchange rate mechanism becomes insufficient - if it is treated as the only mean of coordination faced with the plurality of articulation and interaction processes that involve the characters, the territories and the institutions culturally distinguished. This theoretical contextualization of the economic conventions is revealed in a significant instrument to treat aspects involving the degree of trust, reciprocity, the tacit approvals and the value judgments in a clear approach among the economical, social and political sciences. The objective of the present work is proposing a theoretical reflection based on the conventional approach on the characters coordination mechanisms of different border territories.

Key words: Border; Economy of conventions; Commercialization; Territories.

\section{Introdução}

$\mathrm{O}$ avanço dos debates com relação às peculiaridades das zonas de fronteira tem permitido ampliar a compreensão de uma diversidade de temas como as questões da integração, dos fluxos comerciais e migratórios, da cultura, das relações de trabalho, da estrutura de poder, do meio ambiente, entre outros. Na América do Sul, em face das características de seus países em desenvolvimento e dos reflexos da globalização, as zonas de fronteira ganham uma atenção especial devido às especificidades das dinâmicas de relações sociais e espaciais desses territórios, que exigem uma leitura cuidadosa da realidade para compreensão dos fenômenos peculiares dessas regiões.
\end{abstract}


MAX, C.Z. \& OLIVEIRA, T.C.M. de. As relações de troca em região de ...

A economia das convenções, vertente do institucionalismo sociológico, constitui em uma tentativa analítica voltada para responder as interrogações das questões centrais da economia e das ciências sociais, através de um programa de pesquisa ambicioso que procura uma unificação das ciências econômicas, sociais e políticas, em um esforço para suprir as lacunas das análises reducionistas, através dessa transdisciplinaridade (BOYER, 2006).

Ao propor uma pluralidade de modos de coordenação econômica através da hipótese da racionalidade interpretativa dos valores, numa clara incursão aos aspectos cognitivos na economia, essa corrente teórica busca apreender os processos de coordenação que, de certa forma, ampara a instituição das redes de comercialização entre os indivíduos e entre entidades privadas, complementada pelas noções de territorialidade.

A economia das convenções trata insuficientemente a questão da territorialidade, o que certamente é um paradoxo, uma vez que a proximidade é uma noção central desse aporte teórico. O avanço pretendido é propor uma reflexão teórica onde as atividades dos circuitos locais fronteiriços de comercialização possam ser analisadas através dos pressupostos da economia das convenções, sem perder a noção das territorialidades peculiares das zonas de fronteira, o que de fato, constitui em suas diversas tipologias. Os estudos sobre os territórios também ganham importância nesse contexto pela imensa necessidade de buscar entendimentos contemporâneos sobre as contradições entre o global e o local; as proximidades e as relações intra e extraterritoriais são exemplos claros da revitalização dos lugares.

Dessa forma, justifica-se o desenvolvimento deste trabalho para buscar compreender, sob a ótica convencionalista, o ambiente propício ao desenvolvimento territorial de atividades econômicas, onde a reputação e a confiança podem, em maior ou menor grau, contribuir para a criação, o fortalecimento e a manutenção das redes de cooperação, um dos essenciais elementos da competitividade contemporânea. 
MAX, C.Z. \& OLIVEIRA, T.C.M. de. As relações de troca em região de ...

Este trabalho está dividido em duas partes: a primeira resgata as noções da economia das convenções e sua importância para a análise das interações entre os indivíduos em situações de incerteza radical e a segunda busca contextualizar a noção de territorialidade e fronteira ao objetivo postulado. A pesquisa exploratória foi desencadeada pelas premissas estabelecidas através de uma revisão bibliográfica pertinente ao enfoque desenhado.

Os objetivos deste artigo são baseados por duas orientações distintas: a primeira, a de propor a aproximação dos aportes teóricos da economia das convenções e sobre o papel das fronteiras na discussão sobre a mercantilização dos lugares e segunda, propor uma discussão sobre a influência das convenções na análise das relações que envolvam a racionalidade coletiva - e sua legitimidade - no contexto micro-regional. A hipótese defendida é que a inclusão do aporte convencionalista complementa e amplia a compreensão dessas relações na ótica das ciências sociais e políticas, e que pode permitir uma melhor discussão sobre as peculiaridades da comercialização fronteiriça. Apesar de não se constituir em novidade, a recorrência ao aporte da economia das convenções é propositalmente objetivada para aumentar sua discussão nas produções científicas sobre o institucionalismo sociológico na economia e para aproximação à geografia regional.

\section{As contribuições da economia das convenções}

A gênese da economia das convenções repousa sobre as insatisfações dos aspectos a-social e a-histórico que caracterizam a abordagem da economia neoclássica e tem suas raízes estritamente ligadas ao desenvolvimento do neo-institucionalismo no início da década de 70. A escola neo-institucional surgiu para elucidar o papel desempenhado pelas instituições na determinação de resultados sociais e políticos, além de proporcionar uma ampla perspectiva teórica com suas variadas tendências, o que favorece uma diversidade de estudos sobre rotinas, aprendizagem, racionalidade limitada e incerteza. A análise da ação econômica passa de uma integração plena e efetiva de estruturas relacionais e 
MAX, C.Z. \& OLIVEIRA, T.C.M. de. As relações de troca em região de ...

institucionais sem as quais não se podem contextualizar essa mesma ação em níveis de indivíduos, firmas e organizações (PLOCINICZAK, 2002).

Resultado das aproximações interdisciplinares que favoreceram a formação de um corpo teórico capaz de analisar os mercados como formas de coordenações sociais caracterizadas por dependências, imprevisibilidades, conflitos e estruturas distantes da visão consagrada da teoria do equilíbrio geral (ABRAMOVAY, 2004), a economia das convenções surge na metade da década de 80 na França, para criar um diálogo entre a economia institucional e a sociologia econômica, partindo do pressuposto que a autonomia individual dos agentes econômicos deve permite explorar uma pluralidade de formas de coordenação necessárias para o entendimento dinâmico do funcionamento das organizações (LEVERGUE et al. 1997, citados por QUEIROZ, 2004). Essa autonomia do agente é influenciada dentro de um contexto dirigido por mecanismos de interação social, ou seja, o comportamento individual é influenciado por um comportamento social (ORLÈAN, 1991). A introdução da noção de convenção revela um aspecto dinâmico das interações e a importância de sua dimensão histórica, indispensável para a análise da coordenação através de regras de comportamento (CHASERANT; THÉVENON, 2001).

Para Batifoulier e Larquier (2001), a convenção se define como uma regra de coordenação de comportamento alicerçada por três características essenciais: a) é arbitrária, b) é vaga na definição e, c) é desconstituída de ameaças explicitas de sanções. Arbitrária no sentido que, para seguir uma convenção é necessário selecionar a escolha coletiva abstendo-se de outras escolhas alternativas individuais, o que possibilita uma coordenação dos comportamentos. Argumentar sobre essa escolha e explicar o porquê dessa decisão não constituem uma necessidade, pois há a aceitabilidade coletiva sobre a decisão tomada, o que denota a convenção como uma forma não explícita de acordo. Esse aspecto revela o caráter vago de sua definição, pois sua prescrição, ou seja, o comportamento a ser adotado não possui uma forma (como um 
MAX, C.Z. \& OLIVEIRA, T.C.M. de. As relações de troca em região de ...

regimento) escrita a se referir. Isso não exclui a possibilidade de existir regras convencionais constituídas por uma ou algumas frases, o que se conclui que as convenções são predominantemente tácitas o que não descarta, em situações muito específicas, a necessidade de estarem configuradas explicitamente.

Boltanski e Thévenot (1991) propõem um modelo para analisar as convenções e parte das situações de conflito onde os atores irão mobilizar argumentos para defender seus pontos de vista e estudar as exigências que pesam sobre a pluralidade de coordenação (o que revela o caráter interpretativo das regras) significando uma pluralidade de interpretações possíveis e por extensão, de mundos possíveis. Essa pluralidade é determinante nas bases do modelo da economia das convenções que qualifica a economia como uma diversidade de formas de coordenação.

Grosso modo, o modelo das economias da grandeza propõe uma teoria da coordenação sob um enfoque da filosofia política e da sociologia e é considerado como a espinha dorsal da continuidade dos trabalhos convencionalistas; a coordenação se estabelece sobre uma base de acordos implícitos quanto a maneira de avaliar bens, pessoas, acontecimentos, etc. Esses autores defendem que é essencialmente necessário compreender o ajustamento efetuado pelos indivíduos para aplicar as regras, cujas as noções de julgamento ou de interpretação são particularmente variáveis de acordo com cada situação. A hipótese de que os acordos se concluem através do que denominam de um sistema comum de valores só pode ocorrer se existir uma linguagem comum entre os diferentes atores, considerado como um princípio superior comum. A esse princípio superior comum que caracteriza cada natureza, dentre uma pluralidade de naturezas que se situam a ações justificáveis, constitui um elemento de aproximação entre os atores formando uma ordem, uma hierarquia dos atores e dos objetos que Boltanski e Thévenot (1991) denominam de "grandeza".

Especificamente, o modelo das economias da grandeza trata das concepções de justificação, de coordenação e da objetividade 
MAX, C.Z. \& OLIVEIRA, T.C.M. de. As relações de troca em região de ...

para colocar em evidência as fortes exigências sobre a ação justificável em um mundo complexo. As ações justificáveis são constituídas de razões, pois por um lado é a razão que guia a decisão racional e por outro as razões de agir são validadas pelas compreensões e objetividades dos atores (THÉVENOT, 1989).

Baseados em trabalhos de filosofia política que delineiam os ideais de harmonia social, Boltanski e Thévenot (1991) extraem seis pontos axiomáticos para a construção de um bem comum, que constituem as formas de coordenação que levam os atores a justificar suas ações em referência a várias ordens de grandeza, com uma relação direta com a qualificação de bens e serviços, conforme quadro 01. Esses autores propuseram seis "mundos" diferentes de coordenação: o mundo doméstico ou ordem da confiança, onde os atores conhecem-se e negociam as qualidades dos produtos; o mundo mercantil, ou ordem de concorrência, onde os atores são capacitados para realizar um julgamento direto da qualidade dos produtos através dos preços; o mundo industrial, ou ordem de eficácia, onde os atores julgam a qualidade pelas normas técnicas implementadas; o mundo de opinião, ou ordem do renome, onde os atores levam em consideração a reputação das empresas ou dos produtos mais conhecidos; o mundo cívico ou ordem do coletivo, onde os atores deliberam sobre a qualidade tomando como referência interesses cívicos como o ambiente, um território ou a proteção a um setor e, o mundo de inspiração, ou ordem de inovação, onde os atores aderem a emergência das idéias inovadoras para julgar a qualidade. Ao aporte inicial, soma-se o mundo por projetos, ou ordem de eficiência, proposto por Boltanski e Chiapello (1999), onde os atores oferecem o julgamento da qualidade pela noção da valorização dos recursos constituintes do produto, sob a perspectiva da legitimação dos benefícios das conexões sociais. 
MAX, C.Z. \& OLIVEIRA, T.C.M. de. As relações de troca em região de ...

Quadro 01: Os mundos do modelo das economias da grandeza

\begin{tabular}{|c|c|c|}
\hline \multirow{2}{*}{ Mundos } & \multicolumn{2}{|c|}{ Grandeza } \\
\cline { 2 - 3 } & Princípio superior & Base das convenções \\
\hline Doméstico & Confiança & Reputação, estima \\
\hline Industrial & Eficácia, performance & Padronização \\
\hline Mercantil & Concorrência & Preço \\
\hline Cívico & Solidariedade & Interesse coletivo \\
\hline Opinião & Prestígio & Reconhecimento da opinião \\
\hline Inspiração & Criatividade & Manifestação de inspiração \\
\hline Por Projeto & Valorização dos recursos & Gestão \\
\hline
\end{tabular}

Fonte: Biencourt et al. (2001), com tradução dos autores.

As definições dos pressupostos de Boltanski e Thévenot (1991) possibilitam compreender as diferenças entre os diversos universos propostos, fornecendo a uma noção de pluralidade analítica da economia das convenções. Entretanto, para o entendimento dos lugares e o uso dos espaços onde as trocas exigem um princípio de equilíbrio relativo (ainda que instável) é necessário incluir a questão da territorialidade dos lugares. Nesse sentido, o aporte central da economia das convenções trata esse importante elemento de forma residual, o que denota que a noção de espaço é exógena a coordenação econômica, o que dificulta as percepções da construção social cuja relação mais direta é o local, este tido como meio de subsistência, zona de refúgio e sujeito de reordenamento territorial e planificação urbana (FARET, 1997, citado por MARIN, 2005, p.3).

Os trabalhos de Storper e Salais (1993), Storper (1995) e Storper (1997) buscam avançar no sentido de analisar as territorialidades da inovação dos mundos de produção sob a perspectiva de uma tipologia entre convenções, produtos, tecnologias e territórios. A coordenação por estruturas cognitivas nesse caso tenta tornar a noção de espaço mais presente na abordagem convencionalista, justificando a diversidade espacial dos modos de coordenação. Entende-se, dessa forma, que a proximidade é inegavelmente uma noção central da economia das 
MAX, C.Z. \& OLIVEIRA, T.C.M. de. As relações de troca em região de ...

convenções; nas zonas de fronteira, essa noção é primordial para o estabelecimento das relações cotidianas nesse milieu geográfico.

\section{A fronteira como elemento de análise micro-regional}

Tradicionalmente, fronteira é dita como limite que separa o terreno doméstico do internacional, é onde inicia e termina a linhalimite do Estado. Por limites, entende-se que são as extremidades das regiões, que ser configura como divisores políticos entre governos de regiões, como as divisões territoriais (dos municípios e estados, por exemplo). Entretanto os limites internacionais possuem um caráter especial por que representam o divisor entre países onde prevalecem suas maiores autoridades políticas (WARF, 2006).

Guichonnet e Raffestin (1974) propõem uma diversidade de funções para a fronteira, levando em consideração o entendimento de que as fronteiras servem a diversos propósitos. Essas funções estão sujeitas as constantes mudanças, podendo até desaparecer, sendo mais provável, de acordo com esses autores, que tenham seus efeitos reduzidos, ocorrendo o que chamam de défonctionnalisation des frontières.

Se as funções da fronteira são marcadas pela presença humana no território, onde exprimem a força, a independência e a soberania, é inevitável pensar que a socialização do indivíduo é intrinsecamente espacial e que as diferenças ocorrem pela diversificação das ações dos grupos sociais que atuam no espaço (JOHNSTON; GREGORY; SMITH, 1994).

Pode-se entender que o termo fronteira (na concepção anglosaxônica) revela uma particularidade distinta, sob dois ângulos, em que a geografia trata o assunto: o primeiro é o termo boundary, cuja significação é a linha limítrofe e o segundo, frontier, cuja noção é a de zona de fronteira (JEANNERET, 1984). Dessa diferenciação pode-se afirmar que a partir da abstração da primeira desenvolvem-se trabalhos por uma variável técnica da fronteira, que indica delimitação e demarcação territorial que substancia os estudos dos conflitos inter-Estados da geografia política. A 
MAX, C.Z. \& OLIVEIRA, T.C.M. de. As relações de troca em região de ...

zonalidade presente na segunda noção, diferentemente, permite ampliar e integrar os diversos aportes das disciplinas sociais, cujo objeto é de estudar os efeitos da fronteira (processos políticos, sociais, econômicos, culturais, entre outros) sobre os grupos e suas relações entre si. A esses dois grupos Jeanneret (1984) propõe uma classificação para os dois entendimentos da fronteira: a "geografia regional", marcada pela aproximação à economia, e "geografia da percepção", que se aproxima das ciências cognitivas.

Neste contexto são válidas as preocupações que decorrem da necessidade de compreensão das peculiaridades das zonas de fronteira onde as noções de limite e liberdade gravitam sob as relações entre territórios distintos e, consequentemente, sob distintas relações de poder, que levam o estabelecimento de novas trajetórias - favoráveis ou não, entre esses domínios diferenciados. Como resposta às transformações políticas, econômicas, culturais e sociais da modernização, esses territórios buscam, através da mutação da própria natureza dos limites e das fronteiras, estabelecerem cenários para a crítica de suas próprias dimensões arbitrárias e para a inserção de ambientes integrados (HISSA, 2006, p.37).

Ao afirmar que "[...] Existe vontade/necessidade: de um lado é sempre avançar sobre os limites da legislação civil, fiscal e normativa; do outro, ao mesmo tempo, preservar os seus (para o outro)[...]" Oliveira (2005, p. 379) revela a dimensionalidade contraditória desses espaços periféricos e, é por essa caracterização conflituosa que invoca a pouca presença de homogeneização que House (1980, p. 474) aponta a predominância da política turbulenta na fronteira entre duas nações (na maioria das vezes pelos interesses historicamente opostos), que, somadas mais recentemente às questões ambientais, aos nacionalismos exacerbados, ao terrorismo e as discrepâncias estruturais, consolidam percepções ambíguas sobre os limites dos territórios nacionais.

A descontinuidade política, administrativa e social que caracteriza esse meio geográfico, exige uma análise cuidadosa e 
MAX, C.Z. \& OLIVEIRA, T.C.M. de. As relações de troca em região de ...

complexa das relações cotidianas - sociais, comerciais e econômicas, sendo, entretanto, indispensáveis para o amadurecimento e para a evolução das práticas de integração e de cooperação nessas regiões. Por isso, diferentes escalas das dimensões sociais assimétricas impedem olhar os "outros" da fronteira de maneira imperceptível, que represente ausência plena de qualquer tipo de interação, especialmente entre as fronteiras dos países em desenvolvimento. Nesse sentido, Oliveira (2005) afirma que a fronteira é um espaço bipolar e multiforme, um meio geográfico que exige uma quase necessidade de se transportar seus limites, fazendo alusão que os habitantes fronteiriços coexistem em ambientes de delicados fenômenos que só ali se desenvolvem. Nas palavras do autor $(2005$, p.380) "Este ambiente plural transformou as fronteiras em territórios singulares. São singulares em relação ao território-nação e singulares entre si - cada fronteira é uma (grifo do autor) fronteira" Assim, afirma-se que as áreas limítrofes dos países possuem características peculiares que as tornam em um espaço de tensões e simultaneamente espaço de estabelecimento de integração. Essa dualidade revela a necessidade de se estabelecer separações e limites, com observação das diferenças culturais e a preservação da soberania dos países e, também, a de se exercitar práticas sociais e trocas comuns. Fronteira é ao mesmo tempo, área de separação e de aproximação, linha de barreira e espaço polarizador (CASTELLO, 1995).

Dessa forma, pode-se pensar que, paradoxalmente, a distância dos centros econômicos nacionais e as disparidades dos cenários político-econômicos desenvolvidos pelas trajetórias históricas diferentes, criam nas zonas de fronteira a quase necessidade de várias proximidades entre si, nem sempre benéficas, duradouras e eqüitativas para os lados envolvidos, mas cuja permissividade leva a um inexorável redimensionamento da convivência fronteiriça (OLIVEIRA, 2005).

$\mathrm{Na}$ busca da integração, as instituições que norteiam as ações dos atores fronteiriços são construídas pela convergência de interesses, em níveis supranacionais, de Estados e em níveis locais, 
MAX, C.Z. \& OLIVEIRA, T.C.M. de. As relações de troca em região de ...

gerando diferentes formas de trocas econômicas. As instituições formais e informais, estabelecem um gride de permeabilidade entre as interações locais que possibilitam o que Cuisinier-Raynal (2001) chama de zonas de circulação transfronteiriça, que, ao longo do tempo, podem constituir em ambientes com níveis de cooperação satisfatórios, mesmo com desigualdades e ambigüidades. Por outro lado, essas mesmas instituições influenciam diretamente (ainda que temporariamente) no grau de porosidade da fronteira quando, no exercício das interações, interesses divergentes afloram e deixam prevalecer a noção do estrangeiro como uma externalidade social maléfica, o que pode desencadear reciprocidades instantâneas, exigentes de ações diplomáticas estatais. Nesse sentido, Sayad (1998) afirma que a ausência na participação política no país receptor faz do estrangeiro um hospedeiro no sistema de comércio local, tolerável pelos interesses de complementaridades temporais e circunstanciais.

Zonas de transição entre diferentes sociedades, centros de poder, etnias e culturas, as zonas de fronteira apresentam assimetrias políticas, econômicas, culturais e sociais que caracterizam a co-existência de diferentes regimes regulatórios (ANDERSON; O'DOWD, 1999) o que constitui, de fato, diversidade de situações que marcam essas regiões, principalmente as situadas na América do Sul, onde foram historicamente configuradas pelas disputas nacionais. A proximidade geográfica e o distanciamento étnico, institucional, político, social, cultural e econômico, criam um gradiente heterogêneo que diferencia uma região de fronteira da outra, onde o grau de conflito e de cooperação pode proporcionar uma tensão nas relações das sociedades que ali mais ou menos interagem.

Reflexo de uma concepção de zonas de fronteira como regiões defensivas, fechadas e orientadas para dentro, as duplicidades de infra-estrutura existentes nas regiões fronteiriças evidenciam a concorrência entre as mesmas, o que leva a um paradoxo, uma vez que em muitas vezes compartilham problemas homogêneos, o que as obrigam a formar alianças ainda que para 
MAX, C.Z. \& OLIVEIRA, T.C.M. de. As relações de troca em região de ...

competir com outras díades ou tríades de seus próprios países ou de países limítrofes (MACHADO; STEIMAN, 2004).

Assume-se o pressuposto que as fronteiras possuem algum nível de trocas locais, espontâneas ou promovidas, num movimento de complementaridades boas ou não, nas palavras de Oliveira (2005), cujo modelo espacial se posicione entre o tipo capilar e o tipo sinapse, conforme proposta metodológica de Cuisinier-Raynal (2001). Os fluxos de comercialização na região fronteiriça podem ser entendidos pelo grau de interação e integração (espontânea ou não) que, pela própria necessidade de diminuir o isolamento dos centros econômicos nacionais, respondem pela diversificação endógena de bens de consumo nesses territórios.

House (1980) desenvolve um quadro teórico que contribui para o entendimento das dinâmicas funcionais dessas regiões, utilizando-se para isso da geografia, da sociologia, da política e da economia para denominar a noção de double peripherality, que caracteriza as zonas de fronteira como regiões de pouco peso político, sem a força das elites tomadoras de decisões e por grandes disparidades econômico-sociais.

Oliveira (2005) enfoca o processo de trocas em um interessante conjunto de interações sociais e materiais que ocorrem na fronteira, que possibilita uma classificação conforme seus níveis de integração (funcional e formal), numa tipologia de relações fronteiriças. Para esse autor, as seguintes situações podem constituir nessa classificação proposta: fronteira morta, território perigoso, fronteira viva e fronteira burocrática. Assim, a situação A que indica uma baixa integração formal com baixa integração funcional é classificada como fronteira morta, o que denota uma passividade entre os aglomerados urbanos fronteiriços. Território perigoso é a classificação da situação $\mathrm{B}$, que, pela excessiva informalidade, reflete presença mínima do estado e das instituições. A conjunção da alta integração formal com a alta integração funcional revela uma dinâmica de interações sustentadas pela confrontação das lógicas econômicas e políticas (RAFFESTIN, 1993, citado por OLIVEIRA, 2005), o que o autor 
MAX, C.Z. \& OLIVEIRA, T.C.M. de. As relações de troca em região de ...

classifica como fronteiras vivas (C). Por fim, a situação D configura a fronteira burocrática (alta integração formal com baixa integração funcional), onde prevalece a potencialização da competitividade do meio geográfico com relação a outras regiões, com forte aparato estatal e empresarial e com pouco espaço para a construção de elos sociais entre os atores transfronteiriços.

Nesse meio geográfico os mundos de justificação ganham particularidades em face da sociodiversidade das populações fronteiriças que, pela força da quase necessidade de interagirem espontaneamente sob diversas formas, possuem convergências e divergências naturais da presença simultânea de culturas distintas.

Nesse sentido, trabalha-se com a hipótese da existência de interações entre dois aglomerados urbanos fronteiriços (conurbados ou semi-conurbados) e que os circuitos de comercialização envolvem desde produtos transnacionais como produtos de origem local, gerando diversas formas de trocas, de acordo com a figura 01 .

Se por um lado o sistema local formal é geralmente formado por médios e grandes distribuidores de produtos na zona de fronteira, cuja caracterização predomina o mundo mercantilindustrial (onde a interatividade pode ocorre tanto do lado de origem como do lado de destino, através do comércio exterior), por outro o sistema funcional é representado por pequenos comerciantes, ambulantes e feirantes que atuam no aglomerado de origem e, quando fatores políticos e cambiais são determinantes, desempenham suas atividades do outro lado da fronteira. Neste caso, pode ocorrer o retorno tanto de produtos alimentícios como produtos manufaturados no país de origem, de forma clandestina (evidentemente surgem com essa prática, situações de conflito decorrentes da invasão privada em espaços públicos fronteiriços, além do problema do descaminho, que exigem esforços políticos bilaterais para serem administrados). 
MAX, C.Z. \& OLIVEIRA, T.C.M. de. As relações de troca em região de ...

Figura 01: Convenções e relações fronteiriças

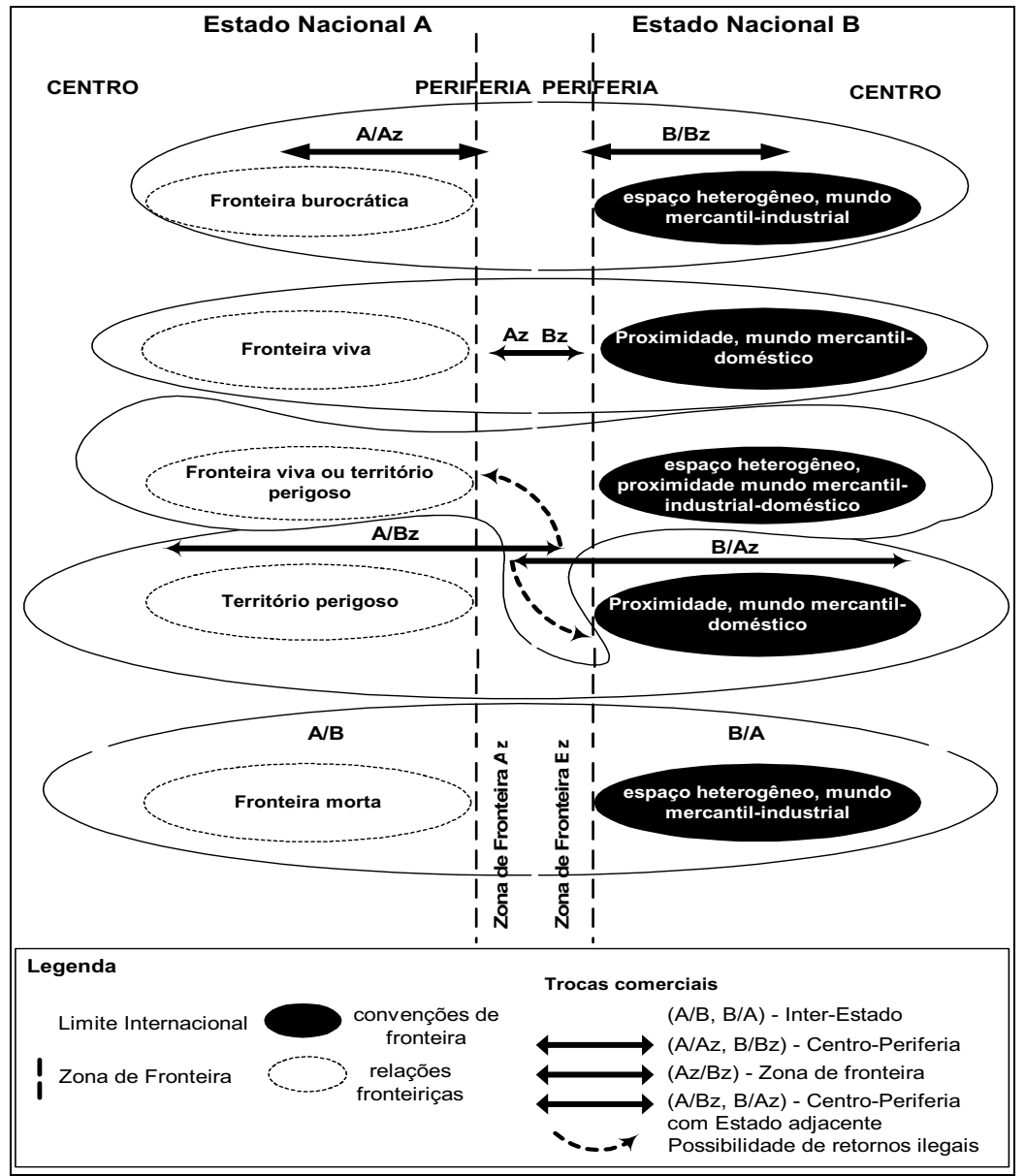

Fonte: elaboração dos autores, a partir de House (1980).

O mundo mercantil-doméstico é adequado para entender esse circuito, onde a venda direta é favorecida pela proximidade e cuja relação interpessoal é influenciada pelo preço e pelos laços de confiança e de reputação, em menor ou maior grau, decorrentes da 
MAX, C.Z. \& OLIVEIRA, T.C.M. de. As relações de troca em região de ...

historicidade entre as duas populações distintas culturalmente As relações oportunistas ocorrem até porque a caracterização principal do sistema de trocas entre nacionais de fronteira é a venda à vista, mas as incertezas radicais (qualidade dos produtos, por exemplo) exigem o estabelecimento de convenções para que o circuito relacional mantenha-se ativo e sustentado ao longo de determinado tempo.

No nível intermediário apresentam-se os médios comerciantes que revendem os produtos para os pequenos comerciantes e vendedores autônomos, tanto do lado de origem como para o outro da fronteira, sendo neste caso muito dependente das variações cambiais que, favorecem ou não, as relações de troca com os estrangeiros. $\mathrm{O}$ mundo mercantil caracteriza esse modo de interação comercial, com produtos globais (muito dos quais constituídos de fraudes), e produtos nacionais que podem retornar ao país de origem pelo comércio clandestino feito por pequenos vendedores ou ambulantes. Os produtos globais comercializados na região de fronteira constituem, por um lado, em desvantagem para a produção/comercialização nacional do país vizinho, mas por outro provoca o fenômeno do turismo de compras, que impulsiona o movimento transfronteiriço.

Em todos os casos, apesar da existência de características singulares, são suscetíveis do fortalecimento das relações de troca, criando um ambiente local difuso. Os acordos implícitos, os julgamentos de valor e um necessário clima de confiança são essenciais para a ocorrência das transações que, pela própria assimetria natural entre os dois lados da fronteira, são importantes no desenvolvimento das complementaridades. O sistema de regras na fronteira exige diferentes critérios de avaliação coletiva para a obtenção de uma legitimidade, mesmo transitória, associada às convenções e interesses, por vezes, conflituosos.

\section{Considerações finais}

Esta reflexão teórica buscou introduzir a questão das regras de comportamento - convenções que norteiam as decisões individuais no contexto coletivo, caracterização gradiente nas relações de fronteira e que contribui de forma a potencializar novas 
MAX, C.Z. \& OLIVEIRA, T.C.M. de. As relações de troca em região de ...

formas de interação econômica e social em situações assimétricas. Os problemas de coordenação e/ou de cooperação que operam na fronteira exigem o conhecimento das capacidades reflexivas dos indivíduos de interrogar a sua identidade e de aderir a uma convenção de bem comum entre dois territórios distintos. $\mathrm{Na}$ fronteira, muitas vezes a representatividade das intenções pessoais exige um julgamento crítico de suas próprias preferências e conformidade às regras que configuram, tanto de um lado como do outro, o pêndulo entre o conflito e o consenso.

As limitações deste trabalho são evidentes: não aprofunda sobre as situações de conflitos (de toda ordem) que marcam boa parte das regiões de fronteira e não promove a discussão sobre as relações de poder, elemento essencial quando se trata da territorialidade. Além disso, sua análise é restritiva no sentido de se aplicar em determinados tipos de fronteiras em circuitos comerciais (e não sistemas produtivos), o que dificulta aplicações nos demais tipos de configurações fronteiriças. Entretanto, busca contribuir em importante perspectiva interdisciplinar nos estudos das fronteiras sul-americanas, o que implica em subsidiar novos trabalhos e ampliar as discussões sobre esses relevantes espaços territoriais.

Apesar de contraditórios pelas inúmeras situações que podem ocorrer, as relações de troca realizadas em zonas de fronteira revelam em desafios e oportunidades tanto para as políticas públicas bilaterais como para as políticas territoriais dos países da América do Sul. Os mecanismos de coordenação ali estabelecidos, em maior ou menor grau, podem resultar em desenvolvimento de integração de baixo para cima, caracterizandoo territorialmente e com tendência ao processo de fortalecimento nas escalas regionais.

\section{Referências bibliográficas}

ABRAMOVAY, Ricardo. Entre Deus e o diabo: mercados e interação humana nas ciências sociais. Tempo Social, v.16, n.2, nov., p.35-71, 2004. 
MAX, C.Z. \& OLIVEIRA, T.C.M. de. As relações de troca em região de ...

ANDERSON, James; O'DOWD, Liam. Borders, border regions and territoriality: contradictory meanings, changing significance. Regional Studies, v. 33, n. 7, p. 593-604, 1999.

BATIFOULIER, Philippe; LARQUIER, Guillemette de. De la convention et de ses usages. In: BATIFOULIER, Philippe. (dir.) Théorie des conventions. Paris: Economica, 2001. p. 09-31.

BATIFOULIER, Philippe; THÉVENON, Olivier. Interprétation et fondement conventionnel des règles. In: BATIFOULIER, Philippe. (dir.) Théorie des conventions. Paris: Economica, 2001. p. 219-252.

BIENCOURT, Olivier; CHASERANT, Camille; REBÉRIOUX, Antoine. L'Économie des conventions: l'affirmation d'un programme de recherché. In: BATIFOULIER, Philippe. (dir.) Théorie des conventions. Paris: Economica, 2001. p. 193-218.

BLATTER, Joachim. Emerging cross-border regions as a step towards sustainable development?. Disponível em: < http://spaef.com/IJED_PUB/v2n3/v2n3_4_blatter.html>. Acesso em: 10 out. 2006.

BOLTANSKI, Luc; CHIAPELLO, Eve. La nouvel esprit du capitalisme. Paris: Gallimard, 1999.

BOLTANSKI, Luc; THÉVENOT Laurent. De la justification (les economies de la Grandeur). Paris: Gallimard, 1991.

BOYER, Robert. L'economie dês conventions 15 ans après. Un point de vue à partir de la théorie de la regulation. In: EYMARDDUVERNAY, François (dir.). L'économie des conventions: méthodes et résultats. Tome I: debats. Paris: La Découverte, 2006. p.45-66.

CASTELLO, Iara R. Áreas de fronteira: territórios de integração, espaços culturalmente identificados? In: CASTELLO, Iara R.; HAUSEN, Ênio C.; LEHNEN, Arno Carlos; SCHÄFFER, Neiva Otero; SILVA, Pedro C. da; SOUZA, Suzana Bleil de. (orgs.). Práticas de integração nas fronteiras: temas para o Mercosul. Porto Alegre: Ed. da Universidade/UFRG, 1995, p. 15-26. 
MAX, C.Z. \& OLIVEIRA, T.C.M. de. As relações de troca em região de ...

CHASERANT; Camille; THÉVENON, Olivier. Aux origines de la théorie économique des conventions: prix, règles et représentations. In: BATIFOULIER, Philippe. (dir.) Théorie des conventions. Paris: Economica, 2001. p. 35-61.

CUISINIER-RAYNAL, Arnauld. La frontière au Pérou entre fronts et synapses. L'Espace Géographique, n.3, p.213-229, 2001.

FAVEREAU, Olivier. L'Économie des conventions: politique d'un programme de recherché en sciences socials. Actuel Marx, n 17, p.102-113, 1995.

Marchés internes, marches externes. Revue

Economique, v. 40, n. 2, mars, p.273-328, 1989.

GUICHONNET, Paul; RAFFESTIN, Claude. Géographie des frontières. Vendôme: Presses Universitaries de France, 1974.

HALL, Peter A.; TAYLOR, Rosemary C.R.. As três vertentes do neo-institucionalismo, Lua Nova, n. 58, p. 194-223, 2003.

HISSA, Cássio Eduardo Viana. A mobilidade das fronteiras: inserções da geografia na crise da modernidade. ( $1^{\text {a }}$ reimpressão). Belo Horizonte: Editora UFMG, 2006.

HOUSE, John W. he Frontier Zone: A Conceptual Problem for Policy Makers. International Political Science Review, n. 1, p. 456-477, 1980.

JEANNERET, Phillipe. Les effets économiques régionaux des frontières internationales: l'exemple de la frontière franco-suisse de Genéve à Bâle. Neuchatel, Suisse, Université de Neuchatel, Faculté de Droit et des Sciences Économiques, 1984, 347p. (these).

JOHNSTON, Ron J., GREGORY, Derek, SMITH, David. The dictionary of human geography. Oxford: Blackwell Publishers, 1994. 
MAX, C.Z. \& OLIVEIRA, T.C.M. de. As relações de troca em região de ...

MACHADO, Lia Osório; STEIMAN, Rebeca. Limites e

fronteiras internacionais: uma discussão histórico-geográfica.

Disponível em:

http://acd.ufrj.br/fronteiras/pdf/REBECALIADiscBibliog.pdf $>$.

Acesso em: 09 jan. 2006.

MARIN, Luis Fernando Ocampo. México: de lo regional a lo territorial. VI Encuentro de Postgrados Iberoamericanos sobre Desarrollo y Políticas Territoriales: construyendo espacios para la colaboracion regional. Toluca (México), set., 2005, 26p.

OLIVEIRA, Tito Carlos Machado de. Tipologia das Relações Fronteiriças: elementos para o debate teórico-práticos. In:

Território Sem Limites. Campo Grande: Editora da UFMS, 2005. p.377-408.

ORLÉAN, André.(dir.). Analyse économique des conventions. $2^{\mathrm{a}}$ édition. Paris: PUF, 2004.

ORLÉAN, André. Logique walrasienne et incertitude qualitative: des travaux d'Akerlof et de Stiglitz aux conventions de qualité. Economie et Societé, n.14, jan., p. 137-160, 1991.

PLOCINICZAK, Sébastien. Action économique et relations sociales: un éclairage sur la notion d'encastrement chez Karl Polanyi et Mark Granovetter. Centre d'Economie de l'Université Paris Nord, Working Paper n. 07-2002. Disponível em: < http://www.univ-paris13.fr/CEPN/wp2002_07.pdf.>, acesso em: 20 ago. 2006.

QUEIROZ, Napoleão dos Santos. A ciência organizacional póssetenta à luz das vertentes institucionalistas da sociologia e da economia. Salvador: Universidade Federal da Bahia, Núcleo de Pósgraduação em Administração, 2004, 461 p. (tese de doutorado).

RAFFESTIN, Claude. A ordem e a desordem ou os paradoxos da fronteira. In: OLIVEIRA, Tito Carlos M. de. (org.) Território sem limites: estudos sobre fronteiras. Campo Grande-MS: Editora da UFMS, 2005, p. 9-15. 
MAX, C.Z. \& OLIVEIRA, T.C.M. de. As relações de troca em região de ...

SAYAD, Abdelmalek. A Imigração. Ou os Paradoxos da Alteridade. São Paulo: Companhia das Letras, 1998.

SANTOS, Milton. A natureza do espaço. São Paulo: Editora HICITEC, 2 2a edição, 1997.

STEIMAN Rebeca. A geografia das cidades de fronteira: um estudo de caso de Tabatinga (Brasil) e Letícia (Colômbia). Rio de Janeiro, Universidade Federal do Rio de Janeiro, 2002, 117 p. (Dissertação de mestrado).

STOPER, Michael; SALAIS, Robert. Les mondes de production. Paris: EHESS, 1993.

STORPER, Michael. Regional world: territorial development in a global economy. New York: The Guilford Press, 1997.

. The geography of conventions. In: TORRE, Andre; $\overline{\text { RALLET, }}$ Alain. Economie industrielle et économie spatiale. Paris: Econômica, 1995, p. 111-127.

THÉRET, Bruno. As instituições entre as estruturas e as ações. Lua Nova, n. 58, 2003. Disponível em: $<$ http://www.scielo.br/scielo.php?script=sci_arttext\&pid=S010264452003000100011\&lng=pt\&nrm=iso $>$. Acesso em: $01^{\circ}$ out. 2006.

THEVENOT, Laurent. Equilibre et rationalité dans um univers complexe. Revue Economique, v. 40, n. 2, mars., p. 627-655, 1989.

TORRE, André; RALLET, Alain. Proximity and localization. Regional Studies, v. 39, n.1, p.47-59, 2005.

WARF, Barney (Ed.). Encyclopedia of human geography. Florida: Sage Publication, 2006.

Recebido em outubro 2007 Aceito em agosto 2008 
